\title{
Stereoselective Synthesis of 8-Trialkylstannylmenthols
}

\author{
Sandra D. Mandolesi, Nelda N. Giagante, Verónica Dodero and Julio C. Podestá \\ Instituto de Investigaciones en Química Orgánica, Departamento de Química e Ing.Qca., Universidad \\ Nacional del Sur, Av. Alem 1253, 8000 Bahía Blanca, Argentina \\ E-mail: jpodesta@criba.edu.ar
}

\begin{abstract}
Trialkyltin menthones of type 2 are obtained selectively by 1,4 -addition of trialkylstannyl lithium to (-)-pulegone. Reduction of $\mathbf{2}$ with borane in THF using as catalyst the reagent prepared from borane and $(\mathrm{S})$-valinol gave a mixture of the corresponding trialkyltin alcohols 3 (Me: 84\%; n-Bu: 90,6\%) and 4 (Me: 16\% and n-Bu: 9,4\%).
\end{abstract}

\section{Introduction}

Taking into account the excellent results obtained with the (-)-8-phenylmenthyl group as a chiral auxiliary, we considered of interest the synthesis of some organotin analogues. The 8triorganotinmenthyl moiety might affect the stereoselectivity due to its bulk and also to electronic effects. The stereoselective synthesis of these compounds was carried out according to Schemes 1 and 2.

\section{Experimental}

The 1,4-addition of trimethyl- and tri-n-butyl lithium to (-)-pulegone led to menthones of type $\mathbf{1}$ and $\mathbf{2}$ with an average yield of $72 \%$ following standard techniques [1]. Compounds $\mathbf{1}$ and $\mathbf{2}$ were separated by column chromatography (silica gel 60). The reduction of type 2 ketones with borane in THF using (S)-valinol as a catalyst was carried out according to known procedures [2].

\section{Results and Discussion}

The reduction of (-)-menthone carried out with the reagent prepared from borane and (S)-valinol in THF in order to determine the degree of asymmetric induction which can be achieved with this reagent, yielded quantitatively a mixture of (-)-menthol (80\%) and (+)-neo-menthol (20\%), i.e., $60 \%$ of diastereoisomeric excess (d.e.). 


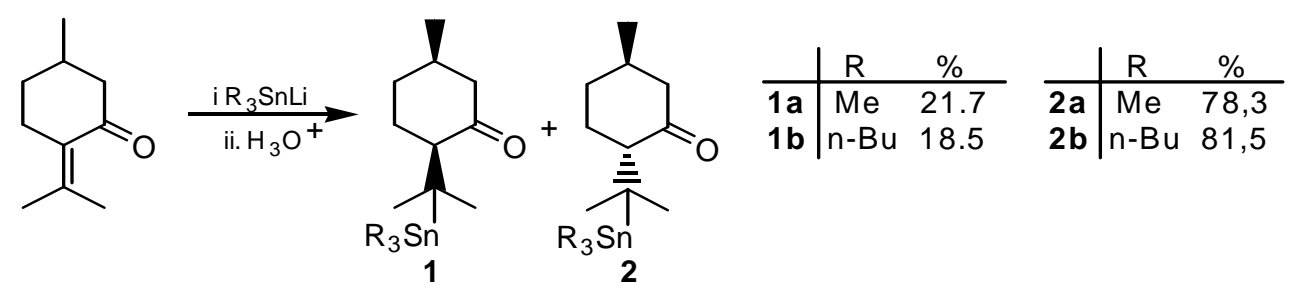

Scheme 1. 1,4-Addition of trialkylstannyl lithium to (-)-pulegone.

Table 1. ${ }^{119} \mathrm{Sn}$ - and some selected ${ }^{13} \mathrm{C}$ NMR values of the new organotin compounds $\mathbf{2 a}$ and $\mathbf{2} \mathbf{b}^{\mathrm{a}}$.

\begin{tabular}{|c|c|c|c|c|c|c|c|}
\hline & $\mathrm{N}^{\circ}$ & $\delta \mathrm{C}_{1}\left({ }^{3} \mathrm{~J}\right)$ & $\delta \mathrm{C}_{2}\left({ }^{2} \mathrm{~J}\right)$ & $\delta \mathrm{C}_{3}\left({ }^{3} \mathrm{~J}\right)$ & $\delta \mathrm{C}_{8}\left({ }^{1} \mathrm{~J}\right)$ & ${ }^{119} \mathrm{Sn}$ & {$[\alpha]_{\mathrm{D}}^{20}(\text { conc. })^{\mathrm{b}}$} \\
\hline & $2 \mathbf{a}$ & $\begin{array}{c}213.42 \\
(17.8)\end{array}$ & $\begin{array}{l}61.25 \\
(7.7)\end{array}$ & $\begin{array}{l}28.41 \\
(31.0)\end{array}$ & $\begin{array}{c}32.59 \\
(243,0)\end{array}$ & 12.7 & $-35.6^{\circ}(0,874)$ \\
\hline $\mathrm{R}_{3} \mathrm{Sn}$ & $2 b$ & $\begin{array}{c}213.16 \\
(16.1)\end{array}$ & $\begin{array}{l}61,40 \\
(6.8)\end{array}$ & $\begin{array}{l}27.94 \\
(\mathrm{NO})\end{array}$ & $\begin{array}{c}26.47 \\
(388.2)\end{array}$ & -8.3 & $-22.2^{\circ}(1,94)$ \\
\hline
\end{tabular}

a) in $\mathrm{CDCl}_{3} ;{ }^{\mathrm{n}} \mathrm{J}(\mathrm{Sn}, \mathrm{C})$ in Hertz; $\mathrm{NO}=$ Not Observed. b) In $\mathrm{CHCl}_{3}$.

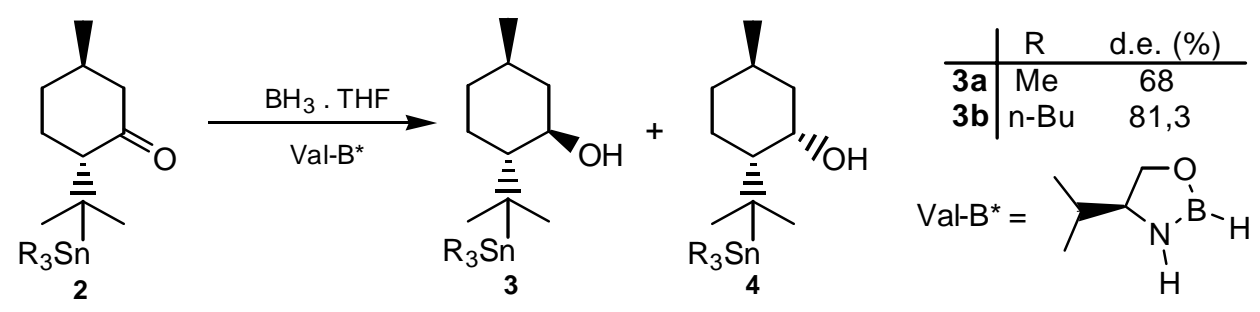

Scheme 2. Stereoselective reduction of trialkylstannylmenthones of type 2.

Under the same reaction conditions, the reduction of $\mathbf{2 a}$ (d.e. $68 \%$ ) and $\mathbf{2 b}$ (d.e. $81,3 \%$ ) led to the corresponding 8-trialkylstannylmenthols with better diastereoisomeric excesses.

Acknowledgements: This work was supported by CONICET (Buenos Aires), CIC (Provincia de Buenos Aires) and Universidad Nacional del Sur (Bahía Blanca, Argentina).

\section{References and Notes}

1. Radivoy, G.E.; Doctor in Chemistry Thesis; Universidad Nacional del Sur 1997.

2. Itsuno, S.; Nakano, M.; Miyazaky, K; Masuda, H.; Ito, K.; Hirao, A; Nakahama, S. Asymmetric Synthesis Using Chirally Modified Borohydrides. Part 3. Enantioselective Reduction of Ketones and Oxime Ethers with Reagents Prepared from Borane and Chiral Amino Alcohols. J. Chem. Soc. Perkin Trans. I, 1985, 2039. 